Available online at https://jurnal.stmikroyal.ac.id/index.php/jurdimas

\title{
OPTIMALISASI APLIKASI MEDIA SOSIAL DALAM MENDUKUNG PROMOSI WISATA GEOL DESA PEMATANG SERAI
}

\author{
Sri Wahyuni $^{1}{ }^{*}$, Mesra $B^{2}$, Eko Harianto ${ }^{1}$, Supina Batubara ${ }^{1}$ \\ Fakultas Sains dan Teknologi, Universitas Pembangunan Panca Budi \\ ${ }^{2}$ Fakultas Sosial Sains, Universitas Pembangunan Panca Budi \\ email: sriwahyuni@dosen.pancabudi.ac.id
}

\begin{abstract}
Amazing attractions are still less widely known to the public, both from the surrounding area and from outside the area, when it has a good tourism potential if it can be promoted properly. Promotions do not necessarily use costly and difficult fees. Promotion can be completed with social media by applying the right technique. People are still a lot less aware and less understand how to optimize social media into promotional media. The purpose of this devotion is to improve the understanding and knowledge of the community, especially in Desa Pematang Serai in optimizing the use of social media as a promotional technique Geol tourism object in the village of Lemongrass. The use of social media can introduce Geol tourism objects that have Dipematang Serai to be known by both domestic and local tourists. Social media is the most appropriate promotional technique in the popularization of Geol tourism objects. With social media promotion to be safe and efficient. The tools used also use a Smartphone and the Internet. Promotion through social media can increase the number of tourists visiting Geol tourist attraction in Pematangserai. The goal of the PKM is to its young teenagers to BUMDES Mozaik who manages the Geol tourism object. Results obtained from PKM activities of the lemongrass Pemtang community experienced an increase in optimizing social media into promotional media.
\end{abstract}

Keywords: social media; promotions; Geol attractions.

\begin{abstract}
Abstrak: Objek wisata Geol masih kurang dikenal masyarakat secara luas, baik dari daerah sekitar maupun dari luar daerah, padahal memiliki potensi pariwisata yang bagus jika dapat dipromosikan secara baik. Promosi tidak mesti menggunakan biaya yang mahal dan sulit. Promosi dapat dilakuakn dengan media sosial dengan menerapkan Teknik yang tepat. Masyarakat masih banyak yang kurang menyadari dan kurang memahami bagaimana mengoptimalkan media sosial menjadi media promosi. Tujuan yang ingin dicapai dari pengabdian ini adalah meningkatkan pemahaman dan pengetahuan masyarakat khususnya di Desa Pematang Serai dalam mengoptimalkan penggunaan Media sosial sebagai Teknik promosi Objek Wisata Geol yang ada di Desa pematang Serai. Penggunaan media sosial dapat memperkenalkan objek wisata Geol yang ada Dipematang Serai agar dikenal oleh wisatawan domestik maupun lokal. Media Sosial adalah Teknik promosi yang paling tepat dalam mempopulerkan objek pariwisata Geol. Dengan Media Sosial promosi menjadi hemat dan efisien. Alat yang digunakan juga menggunakan Smatrphone dan internet. Promosi yang dilakukan melalui media sosial dapat meningkatkan jumlah wisatawan yang berkunjung ke Objek wisata Geol yang ada di Pematang Serai. Sasaran dari PKM ini adalah kepada para remaja khussunya kepada BUMDES Mozaik yang mengelola objek Pariwisata Geol. Hasil yang diperoleh dari kegiatan PKM ini masyarakat pemtang serai mengalami peningkatan dalam mengoptimalakan media sosial menjadi media promosi.
\end{abstract}

Kata Kunci : media sosial; promosi; objek wisata Geol. 
Available online at https://jurnal.stmikroyal.ac.id/index.php/jurdimas

\section{PENDAHULUAN}

Desa Petang Serai adalah salah satu Desa yang terdapat di Tanjung Pura. Mayoritas mata pencarian penduduknya adalah bertani, peternak ikan lele, jangkrik. Desa Pematang Serai memiliki Bumdes Mozaik dimana bumdes tersebut dapat mengelola dana desa dengan sangat baik dan salah satu yang sangat bagus adalah dapat menjadikan aliran sungai menjadi objek pariwisata Geol (Getek Online). Dengan adanya Objek wisata Geol ini diharapkan penduduk dapat menjaga kebersihan sungai dan bersama-sama menjaga lingkungan di Desa Pematang Serai. Kemudian yang tidak kalah penting adalah dengan objek Pariwisata Geo ini dapat meningkatakan pendapatan masyarakat desa pematang Serai.

Pariwisata adalah berbagai kegiatan wisata yang didukung berbagai fasilitas dan layanan yang disediakan masyarakat, pengusaha dan pemerintah (Hermawan, 2016). Pengembangan daerah tujuan wisata didasari oleh potensi wisata yang akan dikembangkan, termasuk potensi fisik dan non fisik. Banyak faktor dapat digunakan dalam pengukuran potensi tujuan wisata, seperti alam, iklim, geomorfologi, hidrologi, flora dan fauna, adat istiadat, kegiatan masyarakat. (Sutedjo and Wardani, 2017). Pariwisata adalah sektor yang potensial dan layak untuk dikembangkan secara inovatif guna meningkatkan tingkat daya saing (Ismail, 2020). Sektor pariwisata berkontribusi terhadap kesempatan berusaha, membuka lapangan pekerjaan dan peningkatan pendapatan masyarakat. Peningkatan kunjungan wisatawan tentunya berdampak positif terhadap penerimaan devisa dan pendapatan asli suatu daerah. Seperti banyak daerah lain yang mempunyai banyak destinasi alam, sungai dan pantai (Jaelani, 2018).

Indonesia merupakan wilayah yang kaya akan ragam keunikan di desa, namun baik masyarakat maupun pengelola destinasi belum terlihat menyadari benar potensi tersebut sehingga penanganan desa yang memenuhi karakteristik sebagai desa wisata tidak dilakukan dengan semestinya. Dibutuhkan identifikasi yang digunakan dalam mengembangkan Model Pemberdayaan Masyarakat Desa dan Penanggulangan Kemiskinan melalui Desa Wisata (Susyanti and Latianingsih 2013). Indonesia memiliki potensi pariwisata yang sangat besar dan sumber daya yang belum sempat dikembangkan secara maksimal oleh sektor swasta ataupun pemerintah. Diharapkan dapat memberi manfaat bagi masyarakat setelah diadakan pembangunan di bidang pariwisata, karena pembangunan ekonomi salah satunya di bidang pariwisata (Haryoko, Aryati, and Ratna, 2020).

Begitu juga dengan Pariwisata Geol masih belum dikenal secara luas oleh sebab itu dibutuhkan promosi. Promosi adalah komponen utama dalam meningkatkan jumlah pengunjung wisata. Promosi yang paling efisien, murah dan mudah adalah dengan menggunakan media sosial atau disebut juga $e$ marketing. E-marketing adalah proses pemasaran merek atau brand menggunakan Internet, terdiri dari berbagai unsur yang menggunakan berbagai teknologi untuk membantu menghubungkan bisnis untuk pelanggan mereka (Nugraha, 2018). Tapi masih banyak masyarakat Desa Pematang Serai khusunya Anggota Bumdes Mozaik yang kurang memanfaatkan media sosial untuk kebutuhan promosi. Promosi pariwisata dan kualitas pelayanan objek wisata memiliki pengaruh positif yang signifikan dan bertampak cukup besar kepada 
Available online at https://jurnal.stmikroyal.ac.id/index.php/jurdimas

kepuasan wisatawan, maka pihak objek wisata alangkah baiknya memperhatikan faktor promosi pariwisata (Oroh, Mananeke, and Sangkaeng, 2015)

Dalam mendukung industri 4.0, pariwisata juga dituntut untuk dapat mengikuti industri 4.0 yaitu dengan Digital Marketing Pariwisata yaitu usaha yang dilakukan dalam mempromosikan serta melakukan pemasalaran sebuah daerah yang memiliki daya tarik wisata dengan memanfaatkan media digital yang sedang trend saat ini (Warmayana, 2018).

Permasalahan setiap objek pariwisata sebenarnya hampir sama yaitu kurangnya promosi yang mengakibatkan objek pariwisata kurang di ketahui dan kurang di kunjungi wisatawan, begitu juga pada objek Pariwisata Geol (Getek Online) yang ada di desa Pematang Serai. Ada beberapa permasalahan yang dihadapi objek wisata Geol yaitu kurangnya Promosi Objek wisata Geol. Kurangnya promosi objek wisata Geol di desa Pematang Serai Tanjung Pura sehingga mengakibatkan kurangnya jumlah pengunjung wisatawan di wisata Geol desa pematang Serai.

Selain itu juga terdapat kekurangnya promosi yang melibatkna penggunaan Media Sosial. Tidak mengetahui dalam penggunaan media sosial dalam mempromosikan objek pariwisata Geol yang ada di desa Pematang Serai. Penggunaan media sosial adalah solusi promosi dan pengenalan objek pariwisata Geol yang paling hemat, efisien dan efektif. Masih banyaknya penggunaan Media sosial yang kurang memanfaatkan untuk kepentingan yang positif. Terutama usia remaja.

Kecanduan internet telah menyerang tak hanya orang dewasa, melainkan pelajar bahkan anak-anak, setelah mengenal internet dan memasuki situs pertemanan yang ada di internet seperti Facebook, Twitter, Instagram dan sebagainya (Sulaa and Betoambari, 2020). Jika dapat diarahkan dengan kegitan positif seperti promosi objek wisata Geol akan berdampak positif.

\section{METODE}

Dalam merealisasikan pengabdian masyarakat ini maka dilakukan terlebih dahulu pendekatan kepada masyarakat melalui sosisalisasi, baik kepada direktur Bumdes Mozaik selaku pemangku ataupun sebagai pengguna nantinya. Setelah sosialisasi dilakukan pelatihan sebagai wujud pengenalan media sosial sebagai media promosi objek pariwisata Geol yang berada di desa Pematang Serai secara Luas. Pelatihan dilakukan di Kantor Kepala Desa Pematang Serai Tanjung Pura. Dalam kegiatan ini juga dilakaukan diskusi dan tanya jawab. Selanjutnya dilakukan simulasi langsung penggunaan media sosial dalam mempromosikan objek pariwisata Geol Di Desa Pematang Serai.

Agar sistem ini berlanjutan maka dilakukan pendampingan terhadap Bumdes Mozaik. Pendampingan dilakukan melalui kordinasi media sosial, whatshap, email ataupun melalui komunikasi menggunakan telepon selular. Pendampingan yang dilakukan oleh tim pelaksana dan juga tiga orang mahasiswa dari Teknik Komputer Universitas Pembangunan Panca Budi Medan. Prosedur kerja yang dilakukan selalu saling berintegrasi.

Seluruh rangkaian prosedur kerja pengabdian masyarakat Optimalisasi Aplikasi Media Sosial dalam Mendukung Promosi Wisata Geol Kepada Masyarakat desa Pematang Serai dapat dilihat pada gambar 1 . 
Available online at https://jurnal.stmikroyal.ac.id/index.php/jurdimas

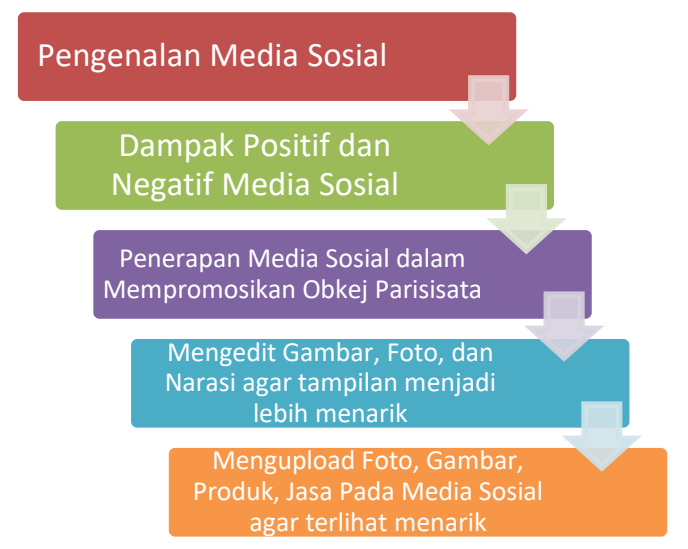

Gambar 1. Metode pelaksanaan PKM

\section{PEMBAHASAN}

Hasil yang diperoleh dari program pengabdian kepada masyarakat ini yaitu peningkatan pengetahuan tentang penggunaan media sosial dalam mendukung promosi objek pariwasata Geol hal ini dapat ditunjukan dari hasil tes yang dilakukan tim pengabdian sebelum dilakukan kegiatan pengabdian kepada Masyarakat dan sesudah kegiatan program pengabdian kepada masyarakat. Sasaran dari kegiatan PKM ini adalah para masyarakat Desa Pematang Serai khususnya anggota Bumdes Mozaik. Peserta yang merupakan para warga desa pematang serai yang sekaligus merupakan anggota dari Bumdes Mozaik dapat mengimplementasikan ilmu yang diperoleh dalam melakukan promosi objek wisata Geol. Peserta pelatihan optimalisasi aplikasi media sosial dalam mendukung promosi wisata Geol kepada masyarakat desa Pematang Serai dalam memperkenalkan objek ariwisata Geol lebih luas lagi sehingga peningkatan jumlah wisatawan yang berkunjung maka berdampak pada meningkatnya pendapatan dan kesejahteraan masyarakat Desa Pematang Serai. Pemateri yang menyampaikan pelatihan terdiri dari 4 orang dosen Universitas
Pembangunan Panca Budi yang telah memiliki kompetensi yang baik di bidang nya masing-masing.

Pada pelaksanaan pelatihan, peran serta mahasiswa prodi teknik komputer sangat membantu untuk menunjang keberhasilan kegiatan pelatihan dan untuk membantu segala sesuatu yang berkaitan dengan hal teknis pelatihan. Dengan tugas membantu mendokumentasi kegiatan pelatihan, editing video dan pembagian cetakan hardcopy materi pada pihak desa pematng serai dan penyediaan alat-alat yang dibutuhkan dalam kegiatan pelatihan, membantu mempersiapkan ruangan tempat pelaksanaan pelatihan, dan pendampingan bagi peserta. Kendala yang dilakukan oleh Tim Pengabdian Mayarakat adalah jarak tempuh yang jauh dari Universitas Pembangunan Panca Budi ke Desa Pematang Serai tanjung Bura kemudian rusak dan kecilnya jalan yang dilalui. Namun kendala yang dihadapi tim dapat diatasi dengan adanya dukungan dan bantuan dari Universitas Pembangunan Panca Budi. Bantuan yang diberikan sarana perjalanan dengan menyediakan Bus yang dimiliki Universitas Pembangunan Panca Budi dalam mendukung perjalanan ke Desa Pematang Serai kabupaten tanjung Pura.

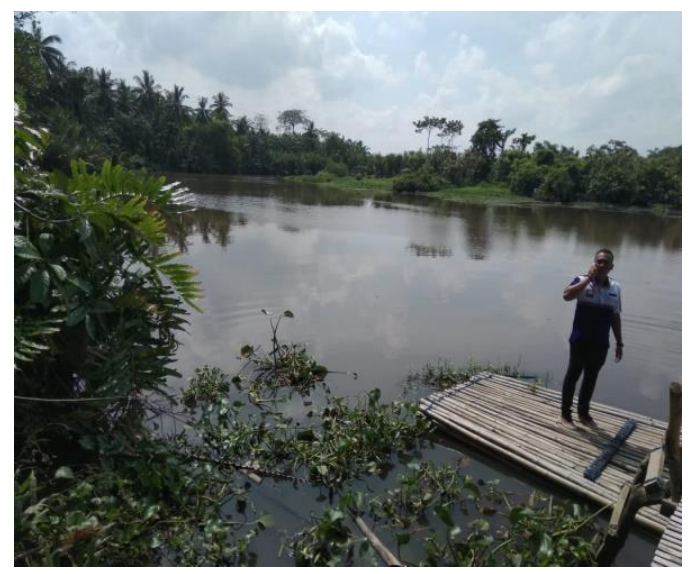

Gambar 2. Sungai Di Pematang Serai 
Available online at https://jurnal.stmikroyal.ac.id/index.php/jurdimas

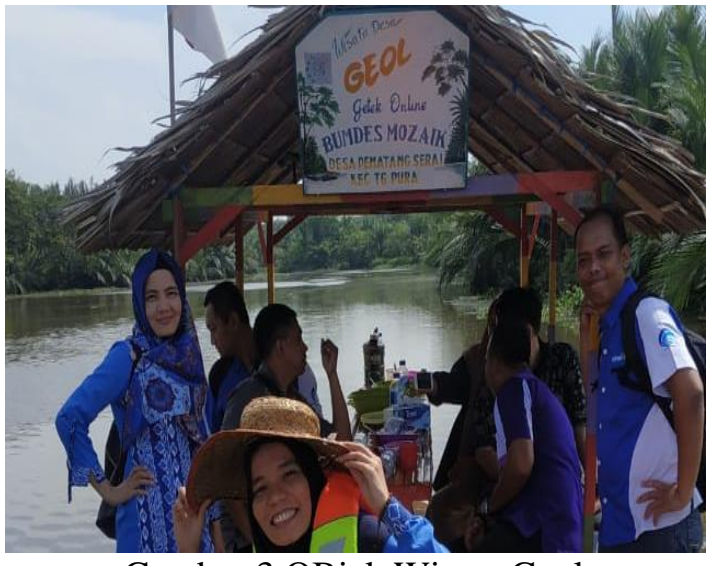

Gambar 3 OBjek Wisata Geol

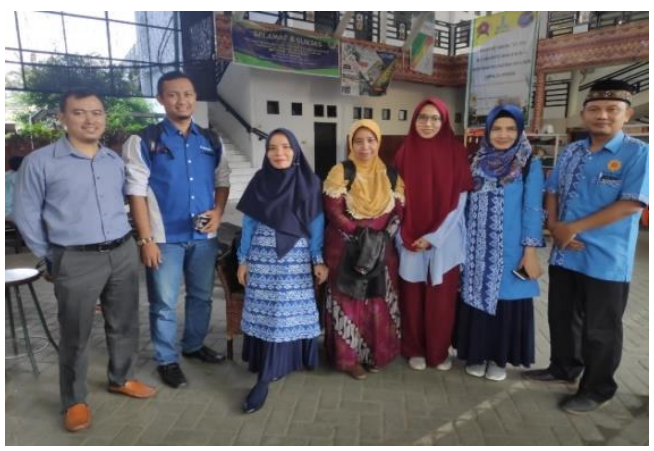

Gambar 4. Pelepasan Tim PKM

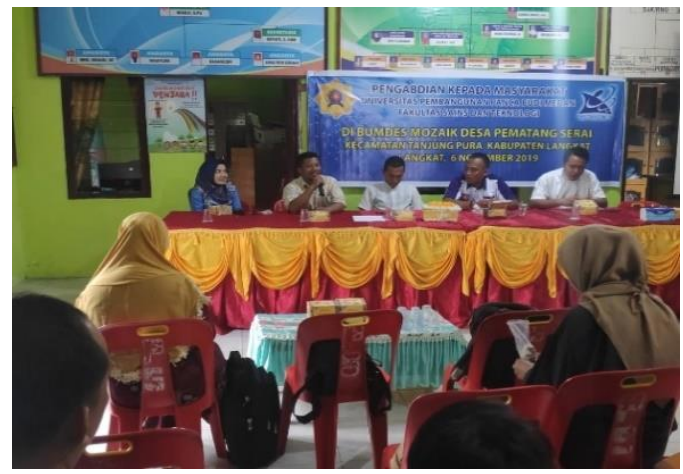

Gambar 5 Kegiatan PKM

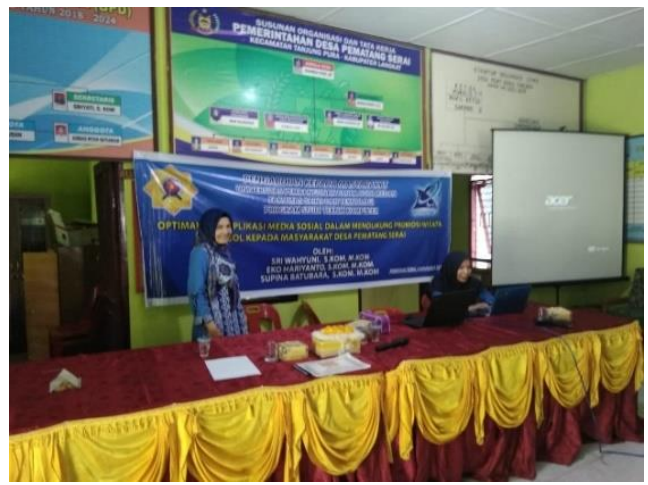

Gambar 6. Kegiatan PKM

\section{SIMPULAN}

Program PKM implementasi optimalisasi aplikasi media sosial dalam mendukung promosi pariiiwisata Geol yang telah dilaksanakan berjalan dengan baik dan lancar serta berdampak baik bagi masyarakat Desa Pematang serai, ini dapat dilihat dari peningkatan pengetahuan dalam bidang media promosi dengan aplikasi media sosial. Implementasi Optimalisasi Aplikasi Media Sosial dalam Mendukung Promosi Wisata Geol Kepada Masyarakat Desa Pematang Serai dalam meningkatkan jumlah wisatawan yang berkunjung dan dapat berdampak pada peningkatan pendapatan dan kesejahteraan hidup masyarakat.

\section{DAFTAR PUSTAKA}

Haryoko, Septian, Ida Aryati, and Damayanti Ratna. 2020. "Potensi Pariwisata Keraton Kasunan Surakarta Di Tinjau Dari Daya Tarik, Lokal Dan Promosi." 04(01): 155-62. Hermawan, Hary. 2016. "Dampak Pengembangan Desa Wisata Nglanggeran Terhadap Ekonomi Masyarakat Lokal.” Jurnal Pariwisata 3(2): 105-17.

Muhamad Ismail. 2020. "Strategi Pengembangan Pariwisata Provinsi Papua." Matra Pembaruan 4(1): 5969.

Jaelani, Abdul Kadir. 2018. "Pengembangan Destinasi Pariwisata Halal Pada Era Otonomi Luas Di Provinsi Nusa Tenggara Barat." Jurnal Pariwisata 5(1): 56-67.

Nugraha, Yudhi Martha. 2018. “Analisis Potensi Promosi Pariwisata Halal Melalui E-." 3(2): 63-68.

Oroh, Sem, Lisbeth Mananeke, and Stela Sangkaeng. 2015. "Pengaruh Citra, 
Available online at https://jurnal.stmikroyal.ac.id/index.php/jurdimas

Promosi Dan Kualitas Pelayanan Objek Wisata Terhadap Kepuasan Wisatawan Di Objek Wisata Taman Laut Bunaken Sulawesi Utara." Jurnal Riset Ekonomi, Manajemen, Bisnis dan Akuntansi 3(3): 10891100.

Sulaa, D I Kelurahan, and Kecamatan Betoambari. 2020. "PELATIHAN CITIZEN JOURNALISM BAGI REMAJA USIA SEKOLAH DI WILYAH PESISIR PANTAI NIRWANA." : 20-27.

Susyanti, Dewi Winarni, and Nining Latianingsih. 2013. "Potensi Desa Melalui Pariwisata Pedesaan."
Ekonomi dan Bisnis 12(1): 33-36.

Sutedjo, Agus, and Intan Kusuma Wardani. $2017 . \quad$ "Strategi Pengembangan Objek Wisata Gunung Beruk Sebagai Wisata Berbasis Masyarakat Di Desa Karangpatihan Kecamatan Balong Kabupaten Ponorogo." Swara Bhumi 5(2): 26-32.

Warmayana, I Gede Agus Krisna. 2018. "Pemanfaatan Digital Marketing Dalam Promosi Pariwisata Pada Era Industri 4.0." Pariwisata Budaya: Jurnal Ilmiah Agama Dan Budaya 3(2): 81. 